\title{
Research on the Innovation Elements In the Process of
}

\section{Technology Innovation}

\author{
Yangguang $\mathrm{Li}^{1}{ }^{1}$ Junju Yue ${ }^{1}$ and $\mathrm{Min} \mathrm{Wu}^{1}$ \\ ${ }^{1}$ School of management and engineering, Zhengzhou University, Zhengzhou, China
}

\begin{abstract}
In order to improve the efficiency of innovation, the process of technology innovation has caused the attention of experts and scholars day by day. But in the process of technology innovation, the research on the extraction and classification of innovation elements needs to be further specific and systematic. Based on the full research on the innovation activities and innovation elements in many innovative fields, this paper elaborates the general process of the formation of innovation principle, and clusters innovation elements in many fields to form nine innovation dimensions, and then segments each innovation dimension into several sub dimensions of innovation. This paper aims to provide theoretical support for the research of innovative methods, and provide help for improving the quality and efficiency of innovation.
\end{abstract}

\section{Introduction}

With the advent of knowledge economy, innovation has become the only effective means to gain competitive advantage, while the improvement of innovation ability needs to be guided by scientific method. The role of the research on methods of technology innovation is to study the process of technology innovation, discover the law of technology innovation, and form a systematic and procedural innovation path, therefore improve the quality and efficiency of technology innovation[1,2] .

The process of technology innovation is to rearrange and optimally design the elements of innovation system, information, process and production process and so on [3]. Analyzing the process of technology innovation will help to excavate the potential law of technology innovation. The research on the process of technology innovation, especially the research on the innovation elements in the process of technology innovation, has become the focus of the attention of experts and scholars day by day. Hu J uses the method of fuzzy cognitive map to identify the causal relationship between factors and constructs an evaluation framework of technological innovation to determine the important factors that influence the path dependence [4]. In the process of technology innovation, the system object should be analyzed structured and multi levels in order to better facilitate the innovation design $[5,6]$. Some experts and scholars proposed that decomposing the process of technology innovation and studying on the innovation mechanism will help to dig the potential law of technology innovation [7, 8]. Meanwhile, existing research on the elements of technology innovation is also increasingly prominent, and the principle of innovation and invention obtained from the coupling of innovative elements and innovation law has been widely recognized $[9,10]$. 
Above all, the existing research has fully analyzes the process of technology innovation, and promotes the development of the research on technology innovation. But most of the existing researches focus on the research of the principle of macro innovation in the process of technology innovation, and it is hardly to see the study on the extraction and classification of micro elements. Based on this, this paper sums up and extracts nine innovation dimensions in the process technology innovation through the systematic analysis on the innovation elements in the existing innovation areas based on the existing research, segments and defines the sub dimensions of each dimension. This paper aims to provide help for accelerating the process of technology innovation and offer methods and theoretical support for improving the quality and efficiency of technology innovation.

The chapters of this paper are arranged as follows. The second part studies the importance and necessity of the research on the elements of technology innovation. The third part studies nine innovation dimensions and sub dimensions induced and clustered after clustering the elements. The fourth part is the conclusion and prospect of this paper.

\section{The importance and necessity of the research on the innovation elements in the process of technology innovation}

After analyzing the process of technology innovation systematically, it is easy to find that the process of technology innovation can be summarized as the process of using the established principles of innovation to act on the elements of system innovation. The principle of innovation and invention are formed through combining different innovation laws and innovations elements. The forming process of the principle of innovation and invention is shown as the Figure 1.

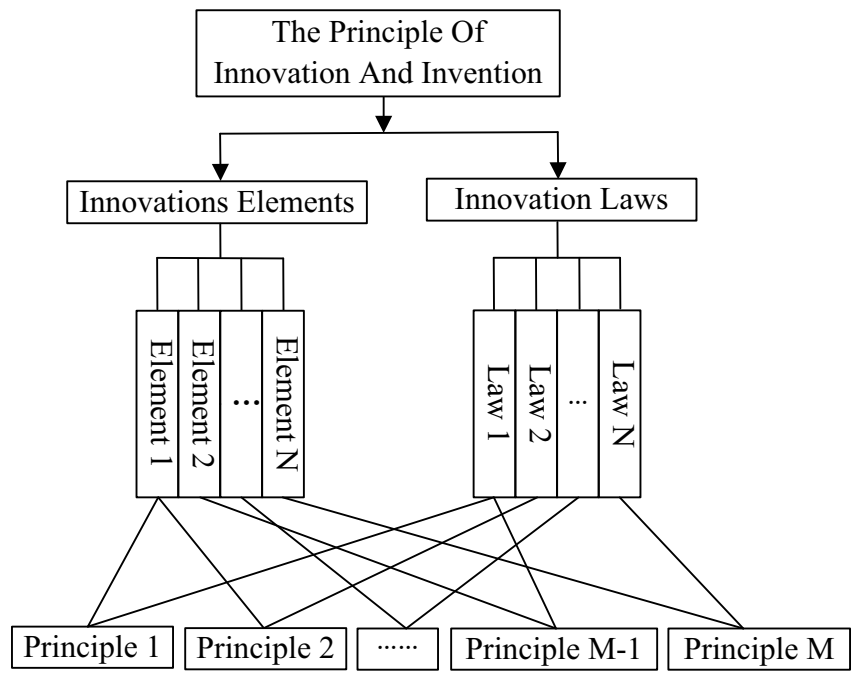

Fig. 1. Forming process of the principle of innovation and invention.

From Figure 1 we can learn that the selection of the innovation elements is the key link in the formation of the principle of innovation and invention. If we can quickly determine the innovation elements, and then use the existing innovation laws to act on the selected innovation elements, the principle of innovation and invention can be formed, and finally realize the technology innovation. Obviously, the way of forming the principle of innovation and invention can improve the efficiency and quality of technology innovation. Based on this, for the development of innovation, it is necessary and important to study the innovation elements in the process of technology innovation.

\section{Research on the innovation elements}

\subsection{Dimension extraction of innovation elements}


Based on the collecting and analyzing on the relevant knowledge and information of the ontology, environment and process of innovation[11-13], in the way of document retrieval and patent mining and through implementing the matrix and semantic analysis for the innovative knowledge, innovative mechanism and innovative principles in multiple innovation areas, this paper finds that innovation changes with the change of innovative elements, structure, system, environment, boundary conditions, time and space changes parameters. At the same time, the new model is constantly generated and transformed into a new form. The process of innovation is the process of the integration of key elements of, construction of network and structuring [14].

Therefore, in order to clarify the innovation elements in the process of technology innovation, and further guide the technology innovation, this paper constructs the knowledge map and patent technology base based on the existing theory knowledge of the innovation, systematically analyzes the innovative activities in many innovation areas, and clusters and analyzes the innovation elements involved in each field, finally condenses and summarize nine innovation dimensions which include space dimension, environment dimension, structure dimension, function dimension, mechanism dimension, material dimension, dynamic dimension, process dimension and human-machine relationship dimension. The process of extraction of the innovation dimensions is shown as Figure 2.

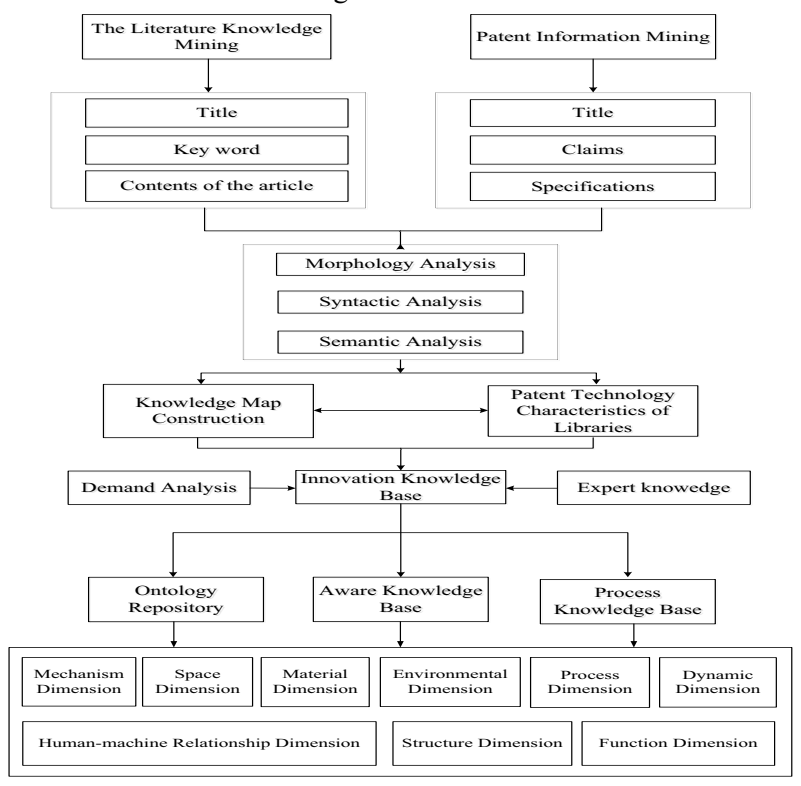

Fig. 2. Process of dimension extraction of the innovation elements.

\subsection{Research on the sub dimensions of innovation}

Innovative inventions in various fields are a complex system engineering involving a variety of innovation elements and methods, while innovative elements in innovation and invention of different areas are different. For example, in the innovation and invention of mechanical devices and transport areas, its innovation elements mainly include the space position and direction of the mechanical components, the optimization of structure relation, the way of function realization and the replacement and substitution of material and so on. While in the innovation and invention of biological medicine field, its innovation elements include biological and pharmaceutical materials, drug mechanism, environment relations and so on, and the elements involved are more specific, diversified.

Considering this, based on the above nine innovation dimensions, this paper comprehensively considers the technical features of several innovation fields, further distributes each innovation dimension into several sub dimensions in order to dig out the elements of technology innovation in the system quickly and improve the quality and efficiency of technology 
innovation through the established innovation dimensions and sub dimensions in the process of technology innovation of different areas. The name and definition of the sub dimensions of each dimension are shown in Table 1 to Table 9.

Table 1. Space dimension and its sub dimensions.

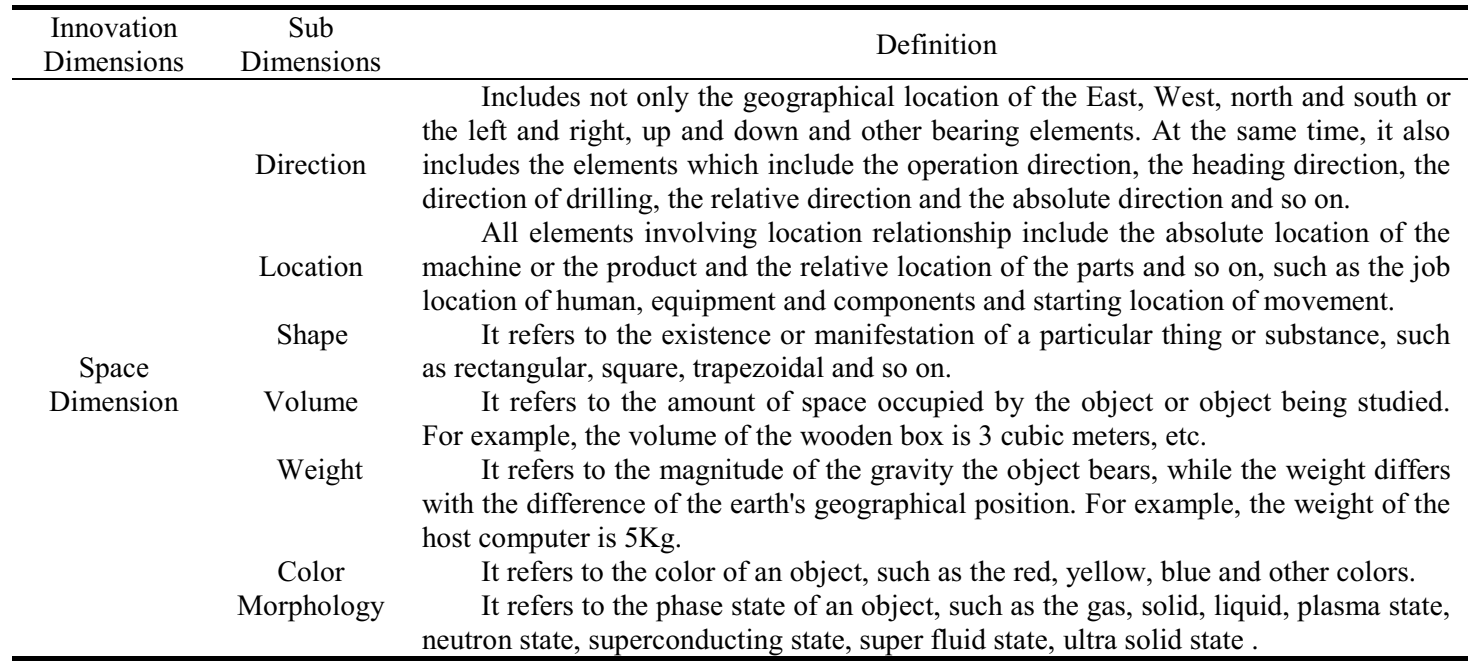

Table 2. Environment dimension and its sub dimensions.

\begin{tabular}{|c|c|c|}
\hline $\begin{array}{l}\text { Innovation } \\
\text { Dimensions }\end{array}$ & $\begin{array}{c}\text { Sub } \\
\text { Dimensions }\end{array}$ & Definition \\
\hline $\begin{array}{c}\text { Environment } \\
\text { Dimension }\end{array}$ & $\begin{array}{l}\text { Environment } \\
\text { Condition } \\
\text { Suspended } \\
\text { Substance }\end{array}$ & $\begin{array}{l}\text { It refers to the natural or induced stress conditions of physical environment } \\
\text { which need to be considered when implement the environmental adaptability and } \\
\text { environmental testing on the products and generate impact on product reliability, } \\
\text { storage and transportation capacity, such as temperature, humidity, illumination, } \\
\text { odor, ventilation and water flow conditions and other factors. } \\
\text { It refers to the solid material suspended in a liquid, which is a generalized } \\
\text { concept. It not only includes inorganic matter, organic matter and silt, clay, } \\
\text { microorganism, etc, which are insoluble to water } \\
\text { but also includes relevant state parameters which include the state and } \\
\text { concentration of the suspension of other solutions and solid materials and } \\
\text { suspension. } \\
\text { It refers to a basic form of matter, employs energy and mass, and it can } \\
\text { transmit the interaction among objects, such as electric field, magnetic field, } \\
\text { gravitational field, atomic radiation, gravity field and so on. }\end{array}$ \\
\hline
\end{tabular}

Table 3. Structure dimension and its sub dimensions.

\begin{tabular}{|c|c|c|}
\hline $\begin{array}{c}\text { Innovation } \\
\text { Dimensions }\end{array}$ & $\begin{array}{c}\text { Sub } \\
\text { Dimensions }\end{array}$ & Definition \\
\hline \multirow{3}{*}{$\begin{array}{c}\text { Structure } \\
\text { Dimension }\end{array}$} & $\begin{array}{l}\text { Space and } \\
\text { geometric } \\
\text { relations }\end{array}$ & $\begin{array}{l}\text { It means the connection of parts and components, including fastening, welding, } \\
\text { bonding, hinge, bundling, traction, adsorption, lift, tolerance and fit relation, } \\
\text { interference fit and other relations. } \\
\text { It refers to the relationship between the component and the component in the } \\
\text { spatial direction. Spatial relations include the upper and lower, before and after, the } \\
\text { left and right, internal and external and other relations. Geometric relations include } \\
\text { grid, box, column beam, shear wall and slab reinforcement, etc. }\end{array}$ \\
\hline & $\begin{array}{l}\text { Stability And } \\
\text { Reliability }\end{array}$ & $\begin{array}{l}\text { Stability refers to the performance of the system which can be kept in a limited } \\
\text { boundary or restored to the original equilibrium state after the system is disturbed. } \\
\text { Reliability is the ability of the product to complete the specified function within the } \\
\text { specified time under the specified conditions. Stability and reliability is a general } \\
\text { term for the ability to resist interference and the function efficiency of the system. }\end{array}$ \\
\hline & Life Cycle & It refers to all links of the product from the design stage to scrap recycling. \\
\hline
\end{tabular}


Table 4. Function dimension and its sub dimensions.

\begin{tabular}{|c|c|c|}
\hline $\begin{array}{l}\text { Innovation } \\
\text { Dimensions }\end{array}$ & $\begin{array}{c}\text { Sub } \\
\text { Dimensions }\end{array}$ & Definition \\
\hline \multirow{3}{*}{$\begin{array}{l}\text { Function } \\
\text { Dimension }\end{array}$} & Movement & $\begin{array}{l}\text { It refers to the movement of objects in space. The trajectory of its motion } \\
\text { includes straight line, curve, rotation and irregular movement. And its state includes } \\
\text { acceleration, uniform, slow and irregular movement. }\end{array}$ \\
\hline & $\begin{array}{l}\text { Production } \\
\text { Efficiency }\end{array}$ & $\begin{array}{l}\text { It refers to the ability to produce sound, light, electricity, heat, magnetic field, } \\
\text { force, information and so on due to some kind of mechanism and principle. }\end{array}$ \\
\hline & $\begin{array}{l}\text { Operation } \\
\text { Mode }\end{array}$ & $\begin{array}{l}\text { It refers to the operation to accomplish a task which includes mechanical } \\
\text { operations, chemical operations, biological operations, electromagnetic operations, } \\
\text { optical operations, nuclear operations, artificial intelligence and other methods. }\end{array}$ \\
\hline
\end{tabular}

Table 5. Mechanism dimension and its sub dimension.

\begin{tabular}{ccc}
\hline $\begin{array}{c}\text { Innovation } \\
\text { Dimensions }\end{array}$ & $\begin{array}{c}\text { Sub } \\
\text { Dimensions }\end{array}$ & Definition \\
\hline $\begin{array}{c}\text { Mechanism } \\
\text { Dimension }\end{array}$ & $\begin{array}{c}\text { Action } \\
\text { Mechanism }\end{array}$ & $\begin{array}{c}\text { It refers to that to realize a certain function, the internal working mode of the } \\
\text { elements in a certain system structure and the elements connect and operate } \\
\text { mutually to generate the rules and principles in a certain mechanism. }\end{array}$ \\
\hline
\end{tabular}

Table 6. Material dimension and its sub dimensions.

\begin{tabular}{|c|c|c|}
\hline $\begin{array}{l}\text { Innovation } \\
\text { Dimensions }\end{array}$ & $\begin{array}{c}\text { Sub } \\
\text { Dimensions }\end{array}$ & Definition \\
\hline $\begin{array}{c}\text { Material } \\
\text { Dimension }\end{array}$ & $\begin{array}{l}\text { Material } \\
\text { Element } \\
\text { Material } \\
\text { Properties } \\
\text { Phase State } \\
\text { Of } \\
\text { Materials }\end{array}$ & $\begin{array}{l}\text { It refers to the type and composition of elements that constitute the material. } \\
\text { It refers to characteristics and properties of materials, which belong to the } \\
\text { inherent nature of the material itself and include thermal properties, mechanical } \\
\text { properties, electrical properties, magnetic properties, optical properties, chemical } \\
\text { properties and other characteristics } \\
\text { It refers to the state of the material and the most common is the solid, liquid, gas, } \\
\text { etc. }\end{array}$ \\
\hline
\end{tabular}

Table 7. Dynamic dimension and its sub dimensions.

\begin{tabular}{|c|c|c|}
\hline $\begin{array}{c}\text { Innovation } \\
\text { Dimensions }\end{array}$ & $\begin{array}{c}\text { Sub } \\
\text { Dimensions }\end{array}$ & Definition \\
\hline \multirow{8}{*}{$\begin{array}{c}\text { Dynamic } \\
\text { Dimension }\end{array}$} & $\begin{array}{l}\text { Dynamic } \\
\text { Source }\end{array}$ & $\begin{array}{l}\text { It refers to the dynamic source of a machine or product, including electric } \\
\text { power, coal power, fuel power, gas power, nuclear power, water power, wind power, } \\
\text { tidal energy, animal power, human thermal power, compressed gas dynamic, } \\
\text { compressed liquid dynamic, elastic energy and other dynamic sources. }\end{array}$ \\
\hline & $\begin{array}{l}\text { Transmission } \\
\text { Mode }\end{array}$ & $\begin{array}{l}\text { It refers to the transmission mode of energy in the process of power } \\
\text { transmission of a machine or product, including mechanical transmission, electric } \\
\text { transmission, fluid transmission, intermediary transmission, etc. It also includes } \\
\text { work, heat transfer, radiation, etc. }\end{array}$ \\
\hline & Energy & It refers to the connection mode between the structural components and the \\
\hline & Transfer & structural components of the machine or the product in the energy transfer process \\
\hline & Process & $\begin{array}{l}\text { between. In the transmission mode of the dynamic system, the connection mode } \\
\text { between the structural component and the structural component includes series, } \\
\text { parallel and series-parallel connection and the like. }\end{array}$ \\
\hline & $\begin{array}{l}\text { Energy Storage } \\
\text { Mode }\end{array}$ & $\begin{array}{l}\text { It refers to the storage of energy and power in the energy transfer process of } \\
\text { products and equipment, including chemical energy storage, energy storage of fluid } \\
\text { compression, fluid energy storage, electromagnetic energy storage, material energy } \\
\text { storage and the like. }\end{array}$ \\
\hline & Intermediary & It refers to the intermediary and media involved in the energy transfer of the \\
\hline & And Media & $\begin{array}{l}\text { product and equipment. Intermediary and medium is a kind of generalized definition, } \\
\text { which includes not only the types, forms and properties of the intermediary and the } \\
\text { medium, but also the interrelation between the intermediary and the medium and the } \\
\text { object of action. }\end{array}$ \\
\hline
\end{tabular}


Table 8. Process dimension and its sub dimensions.

\begin{tabular}{lll}
\hline Innovation Dimensions & Sub Dimensions & \multicolumn{1}{c}{ Definition } \\
Process Dimension & Time Sequence & $\begin{array}{l}\text { It refers to the time related process and the order. } \\
\text { Technology Flow }\end{array}$ \\
It refers to the technology related process and the \\
order.
\end{tabular}

Table 9. Human-machine relationship dimension and its sub dimensions.

\begin{tabular}{|c|c|c|}
\hline $\begin{array}{l}\text { Innovation } \\
\text { Dimensions }\end{array}$ & $\begin{array}{c}\text { Sub } \\
\text { Dimensions }\end{array}$ & Definition \\
\hline \multirow{7}{*}{$\begin{array}{l}\text { Human-machine } \\
\text { Relationship } \\
\text { Dimension }\end{array}$} & human ability & $\begin{array}{l}\text { It includes the basic size of human, human's ability to work, the } \\
\text { limits of various organ function and influencing factors, etc. }\end{array}$ \\
\hline & Human-computer & It refers to the scenario description of the role relationship between \\
\hline & Interaction & $\begin{array}{l}\text { human and the machine with computer. And the human-machine } \\
\text { interface is the form and method of human computer interaction. }\end{array}$ \\
\hline & $\begin{array}{l}\text { Physical } \\
\text { Environment And } \\
\text { Human }\end{array}$ & $\begin{array}{l}\text { It refers to the environment in which people work, such as the } \\
\text { coordination and design of the physical environment which includes } \\
\text { the lighting conditions, noise, music, the color of work space. }\end{array}$ \\
\hline & Security & $\begin{array}{l}\text { It means that the machine or the product in the process of } \\
\text { manufacture and using have no pollution to human body and other } \\
\text { biological, and achieve certain safe using coefficient. To be friendly } \\
\text { requires that the machine or product must be adapted to the user or } \\
\text { operator. }\end{array}$ \\
\hline & $\begin{array}{l}\text { Environment } \\
\text { Protection }\end{array}$ & $\begin{array}{l}\text { It means that the machine or the product in the whole life cycle } \\
\text { including manufacture, using and dumping has no influence on the } \\
\text { environment, which Will not cause the deterioration of the } \\
\text { environment and other conditions. It is different from the environment } \\
\text { dimension. }\end{array}$ \\
\hline & Portability & $\begin{array}{l}\text { It means the convenience of the product or system to achieve } \\
\text { mobility, portability and other function. }\end{array}$ \\
\hline
\end{tabular}

It should be pointed out that the nine innovation dimensions and their sub dimensions proposed in this paper are only the research results of the stage of study on the innovation elements in the process of technological innovation. With the emerging needs of the future and the emergence of new technology features, they can be made necessary changes.

\section{Conclusions and prospect}

This paper clusters and analyzes the innovation activities and innovation factors in each innovation field. It extracts and summarizes nine innovation dimensions in the process of technology innovation, and defines the sub dimensions in each innovation dimension. The research of innovation elements in the process of technology innovation is helpful to improve the quality and efficiency of the innovation. The determination of innovation dimension provides a new way to study the process of technology innovation, and provides help for accelerating the research of innovative methods.

With the continue emerge of new technology and new technologies, the innovation dimension and its sub dimensions proposed in this paper can be improved and enriched at any time. Inducing and constructing the proper innovation laws, combining with the innovation dimensions and studying the coupling mechanism to form a more scientific and complete innovation method system is the direction of the next research.

\section{References}

1. Huang H. Technology Innovation Method Research of Strategic Emerging Industry Based on the TRIZ Theory. Economy \& Management, 2014.

2. Yeo W, Kim S, Park H, et al. A bibliometric method for measuring the degree of technological innovation. Technological Forecasting \& Social Change, 2015, 95:págs. 152-162. 
3. Wohlfeil F, Terzidis O. Critical Success Factors for the strategic management of radical technological innovation. International Ice Conference on Engineering, Technology and Innovation. IEEE, 2014:1-9.

4. Hu J, Zhang Y, Wang Y. Fuzzy cognitive research on influencing factors of technology innovation: In view of path dependence. Portland International Conference on Management of Engineering and Technology. 2015.

5. Xia G. Research about Relation of Working Ways and R\&D Management Effected by Technology Innovation. Applied Mechanics \& Materials, 2010, 40-41:881-886.

6. Harada T. Focusing device as innovation mechanism and cluster growth. Economics of Innovation \& New Technology, 2014, 23(1):49-62.

7. Zhao J, Pablos P O D. Chinese firms' outward direct investment: Technological innovation mechanisms, organizational modes, and improving strategies. Human Factors \& Ergonomics in Manufacturing \& Service Industries, 2010, 20(2):149-160.

8. Mahoney R T. Product Development Partnerships: Case studies of a new mechanism for health technology innovation. Health Research Policy \& Systems, 2011, 9(5):412-427.

9. Paredes-Frigolett H. A novel method for rule extraction in a knowledge-based innovation tutoring system. Knowledge-Based Systems, 2015, 92:183-199.

10. Iacono A, Seido Nagano M. Journal of Technology Management \& Innovation. Journal of Technology Management \& Innovation, 2014.

11. Kodama M. Boundaries Innovation and Knowledge Integration in the Japanese Firm. Long Range Planning, 2009 , 42(4):463-494.

12. Hao J, Yan Y, Gong L, et al. Knowledge map-based method for domain knowledge browsing. Decision Support Systems, 2014, 61(1):106-114.

13. Kim Y G, Suh J H, Sang C P. Visualization of patent analysis for emerging technology. Expert Systems with Applications An International Journal, 2008, 34(3):1804-181.

14. Craig Mauelshagen, Mark Smith, Frank Schiller, David Denyer, Sophie Rocks, Simon Pollard. Effective risk governance for environmental policy making: A knowledge management perspective.Environmental Science \& Policy,2014, 41: 23-32. 